\title{
Lesson Plans as a Mirror: A Close Look at Planning of Work with Underachieving Students
}

\author{
Raisa Guberman ${ }^{1 \dagger}\left(\mathbb{D}\right.$, Dina Tsybulsky ${ }^{2 \dagger^{*}}$ (i)
}

${ }^{1}$ School of Education, Achva Academic College, ISRAEL

${ }^{2}$ Faculty of Education in Science and Technology, Technion - Israel Institute of Technology, ISRAEL

t: Both authors contributed equally to this manuscript

*Corresponding Author: dinatsy@technion.ac.il

Citation: Guberman, R., \& Tsybulsky, D. (2021). Lesson Plans as a Mirror: A Close Look at Planning of Work with Underachieving Students. International Electronic Journal of Mathematics Education, 16(1), em0621. https://doi.org/10.29333/iejme/9375

ARTICLE INFO

Received: 20 Aug. 2020

Accepted: 5 Oct. 2020

\section{ABSTRACT}

The study investigates mathematics lesson plans that teachers produced for re-teaching purposes. Its goal is to determine which aspects of mathematics-content knowledge are expressed in lesson plans on the topic of fractions prepared by primary math teachers and intended for underachieving students, and to see how these aspects are manifested.

The data were gathered in an analysis of forty-nine lesson plans that the participating teachers prepared. The data were analysed in two phases: (1) a category analysis of the plans and (2) a statistical analysis of the data obtained, via cluster analysis and ANOVA tests.

The findings point to four types of teachers in terms of their mathematical knowledge: (1) those whose knowledge is faulty; (2) those who have incomplete or scanty understanding of math but know how to phrase a mathematical idea correctly; (3) those who understand mathematical content well but are not strict about correctly describing the "mathematics" that they teach in the lesson; and (4) those thoroughly versed in mathematics, from whose lesson plans one may infer both correct wording of the mathematical idea and consistently correct use of mathematical concepts and principles. Despite the differences in their content knowledge, teachers of all four types planned to teach their students at a procedural level while attempting to impart conceptual knowledgemost likely because they expect little of their underachieving students. Practical recommendations derived from the study are offered.

Keywords: underachieving math students, teachers' content knowledge, lesson-plan analysis, re-teaching, teachers' expectations

\section{INTRODUCTION}

A major challenge in teaching mathematics concerns working with students who underachieve in class. One possible solution is to 'reteach' these students in individualised settings (e.g., Bellert, 2015; Marzano, 2010). 'Reteaching' in an individualised-lesson format helps students to advance by giving effective and individually tailored support (Bellert, 2015; Lalley \& Miller, 2006). This reflects the application of Hammond and Gibbons's (2005) finding that effective teaching depends largely on fruitful studentteacher interaction. Fruitful interaction comes about pursuant to correct integration of the teacher's content knowledge and beliefs (such as self-efficacy, attitudes toward mathematics, and approaches to the teaching of mathematical content) and may influence teachers' behaviour in class, affect the quality of their teaching, and predict learning outcomes gained both cognitively and affectively (Hill et al., 2018).

According to Bellert (2015), very few studies have looked into structures and processes used in reteaching sessions and still fewer concern themselves with teachers' knowledge and beliefs in this context. Most studies on the topic are concerned with providing recommendations on the planning of these lessons with no accompanying research (Guskey, 2010). We managed to find a very limited number of studies on the topic that were published in mathematics education research journals. To address this gap, the focus of the current study is on the knowledge of teachers who engage in reteaching students who struggle with mathematics. In particular, we investigated various aspects of teachers' knowledge of mathematical content as manifested in the lesson plans that they devised for teaching underachieving students in individualised-lesson formats.

Valk and Broekman (1999) showed that the analysis of teachers' lesson plans is an effective research tool for gauging teachers' existing mathematical and pedagogical knowledge. Recent years have seen a steady increase in the use of teachers' self-produced lesson plans as a research tool. Cavey and Berenson (2005) used lesson plans written by student-teachers to examine the 
development of their mathematical knowledge and teaching strategies via a discussion with them about lesson plans. Cai and Wang (2006) compared lesson plans by teachers in the United States with those produced by colleagues in China, to detect differences in the teachers' construction and evaluation of the representations they used to impart the concept of the ratio. Li et al. (2009) examined a series of plans for sequential lessons to identify teaching practices that are typical of Chinese teachers.

Noticeably, one of the main topics in which students experience difficulties in math studies from fifth grade upward is fractions. Difficulty understanding fractions is conventionally seen as a predictor of further struggle with postprimary level mathematics; hence, we focus on the reteaching of fractions or, to be more precise, on various aspects of rational numbers. Accordingly, the goal of this study was to determine which aspects of mathematics-content knowledge were included and accurately manifested in lesson plans on fractions, prepared by primary-school maths teachers and intended for underachieving students.

\section{LITERATURE REVIEW}

\section{Underachieving Math Students: Who Are They and What Are Their Characteristics?}

Many approaches are used to define students who struggle with mathematics. The terms for these youngsters also vary from one study to the next: students with learning difficulties, struggling students, low-achievers, underachievers, and so on. However, when different groups or subgroups of students are at issue, no single universal term can refer to them all. Irrespective of what we call this population of students, it is their right to learn mathematics and to be taught at a suitable level and under appropriate conditions (Gervasoni \& Lindenskov, 2011). Discussing the difficulty of labelling students who struggle with mathematics, Scherer et al. (2016) divided them into two large groups: those with learning disabilities and those with mathematical learning difficulties (Scherer et al., 2016). Typically, the latter are described as those whose performance in school fails to match expectations (Phillipson, 2008).

In a regular class, students who experience such difficulties are detected using standard achievement tests, considering their performance of miscellaneous tasks, and data from teachers' class observations or conversations (Karsenty, 2010). When a student makes a glaringly large number of errors in a given topic on a comprehensive in-class exam or even on routine practice materials used for learning or relearning in class, the conclusion drawn is that this student has difficulty understanding the topic (Baxter et al., 2001). Teachers must meet the needs of this special, diverse, and varied group of students in the class; by identifying those who experience difficulty with the topic in general they can spare them from experiencing failure in their ensuing studies (Bellert \& Graham, 2017). Furthermore, according to several researchers, this group is by no means small, accounting for $15-20 \%$ of every regular class (Ashman \& Elkins, 2009). Although any group of underachievers is fundamentally a heterogeneous group, consulting multiple studies on the topic suggests that the group may be characterised according to several main attributes, categorised as either cognitive, affective, or social.

The cognitive characteristics of underachieving math students include, but are not limited to, difficulties in remembering mathematical procedures (Karsenty et al., 2007), continual seeking of teacher's attention, difficulty in advancing by their own efforts (Brophy, 1996), inflexible use of previously accrued mathematical knowledge (Verscchaffel \& De Corte, 1995), and difficulty in coping with the language of mathematics in both reading and writing (Karsenty et al., 2007). All these issues aside, these students have metacognitive difficulties, e.g., in using heuristic methods to solve problems (Keijzer \& Terwel, 2004).

The affective characteristics of students who achieve poorly in mathematics are reflected chiefly in stress and anxiety when they confront the discipline. Namely, underachieving students feel distance and estrangement when they face mathematical content (Karsenty \& Arcavi, 2003), along with experiences of protracted failure that generate fear of the subject (Maloney \& Beilock, 2012). Additional affective characteristics that may impair math studies often include poor motivation to study math, a low sense of self-capacity to understand math content and solve math problems, and a lack of self-confidence to tackle the subject at all (Montague, 2011).

The social characteristics of a group of underachieving students are related to the fact that they are given less time and encouragement to participate in the classroom math discourse, which mitigates their capacity to broaden and develop their ability to 'talk maths'. Consequently, they refrain from speaking out in class and expressing their thoughts, ways of solving problems, uncertainties, and so on (Straeler-Pohl et al., 2014).

These characteristics are meaningful when planning to work with these students. Teachers' knowledge and beliefs are, in fact, predictors of their success in working with such students and of their desire and willingness to advance them, both in regular teaching and in reteaching.

\section{Planning Individualised Lessons for Underachieving Students in a Reteaching Setting}

Individualised math lessons for underachieving students are meant mainly for reteaching. That is, these lessons take up matters that the students had studied in class and had not managed to master as expected. This kind of student failure, as noted above, is revealed through standard tests, students' difficulty in carrying out class or homework assignments, or conversations with the teachers. In such cases, teachers are called upon to reteach the material in question. Although in reteaching the teacher repeats the content in which the students failed (Marzano, 2010), to render a different outcome, the reteaching must be more effective and has to respond to each underachieving student's personal scholastic needs (Guskey, 2010). This makes reteaching part of a mathematics teacher's daily practice. Reteaching requires a set of instructional behaviours and strategies that overlay the teacher's mathematical knowledge and beliefs about the content and teaching of mathematics and which should be part of every teacher's 'toolbox' (Bellert, 2015). The question, then, is as follows: What comprises this toolset and on what is it based? 
What needs to be addressed so that the reteaching will be better suited to the needs of underachieving students? Below we look at several research recommendations that are relevant to the proposed inquiry and that emphasise the mathematicalpedagogical knowledge that the math teacher needs.

The first recommendation derived from these studies is that reteaching should take place in small groups, because this gives students more opportunities to test themselves in problem-solving, on the one hand, and receive immediate teacher feedback, on the other hand (Bryant et al., 2008). Working with a small group of students comprised of only those who have trouble with a given topic has several advantages. First, organising the teaching in this manner allows the teacher to adjust the pace of teaching and to provide immediate responses when necessary (Stein et al., 2004). Small-group work and a slower learning pace allow the students to engage in problem-solving and processive thinking in an optimal format, devoid of pressure from more advanced peers (Morgan et al., 2015). Importantly, however, not all small-group work helps struggling students to advance. In several studies, it was found that group work leads to a shared outcome; however, work in heterogeneous groups composed of students with different abilities in mathematics study and joint work of all members of the group in solving the problem are not recommended for underachieving students in math and even have adverse effects on their learning processes (Le et al., 2006)

The second recommendation for teaching underachieving students is to focus on critical content (Archer \& Hughes, 2011). This means teachers should address the exact content of the intended lesson, including its problem-solving strategies, concepts, skills, rules, and so on. More specifically, this entails defining the mathematical idea or theme that will accompany the entire lesson (Bellert, 2015). According to Kameenui and Carnine (1998, p. 8), precise formulations of a main idea or ideas are 'keys that unlock a content area for a broad range of diverse learners'. Planning the entire lesson according to a single well-formulated idea allows students to gain a conceptual understanding in addition to practising procedures or algorithms (Wyatt-Smith et al., 2011). Furthermore, teachers that design their lesson around an explicit mathematical idea are able to steer the lesson to address the specific skill they expect their students to gain and the precise knowledge that should be conveyed and acquired by the end of the lesson (Isoda et al., 2007). This lesson planning approach also helps teachers convey a coherent mathematical idea and develop it gradually throughout the lesson (van de Walle et al., 2013).

An additional recommendation that emerges from the research literature concerns the type of knowledge taught in the reteaching lesson. In a broad overview of difficulties in math studies, Scherer et al. (2016) presented numerous intervention studies that dealt with various teaching methods for underachieving students. Among other things, the researchers noted that when teaching learners who struggle with mathematics, the outcome should be a conceptual understanding of the procedures and operations presented during the lesson. Conceptual learning is that which takes place when students understand the methods that they use to solve problems and establish connections among different mathematical concepts and principles (Guberman, 2016). Many studies demonstrate the effectiveness of this approach. Moser Opitz et al. (2017), for example, studied a group of 120 secondary school students who were shown to have difficulty with basic arithmetic operations. For the purposes of the study, an intervention programme was designed that dealt with developing the learners' conceptual understanding of matters related to the decimal structure and the meaning of arithmetic operations. The results showed that this intervention was highly effective (Moser Opitz et al., 2017).

Another important aspect is the consideration of students' prior knowledge in planning teaching units, in general, and individualised lessons, in particular. As Ausubel (1978, p. 163) said, 'If I had to reduce all of educational psychology to just one principle, I would say this: The most important single factor influencing learning is what the learner already knows'. By implication, ideally, students build new knowledge atop knowledge that they already have, and-assuming that the students possess good quality knowledge-then connections can be established between the new knowledge and their prior knowledge, thus constructing more complex and higher-level schemes (van Kesteren et al., 2014). According to Shing and Brod (2016), prior knowledge plays two central roles in the acquisition of new knowledge: it allows memory to accommodate new knowledge more conveniently and easily and it facilitates long-term memory processes by refreshing prior knowledge.

Drawing on the recommendations and aspects presented thus far, one can produce a profile of reteaching and the way teachers prepare for it: Teachers should contemplate the intended topic of their lesson, i.e., its general structure, the language needed to teach it, and the knowledge required to understand it. To wit, they should consider the matter they intend to impart with two pairs of eyes-"innocuous and suspicious" (Sullivan, 1991). By implication, effective reteaching entails the use of a different approach from that initially invoked, i.e., one based on previous activities but focusing on omissions or errors in students' thinking that occur in various problem-solving situations (Marzano, 2010).

\section{METHODOLOGY}

The purpose of this study was to determine which aspects of mathematical-content knowledge were included and how they were manifested in lesson plans on simple fractions, intended for underachieving students and prepared by primary-school math teachers. In accordance with this purpose, the following factors were considered:

- the mathematical content of the lesson plan (at the general level)

- the type of knowledge taught in the lesson

- the main idea dealt with in the lesson

- the connection to students' prior knowledge

- the use of mathematical language. 
Table 1. Rubric for category analysis of lesson plans

\begin{tabular}{|c|c|c|c|c|c|}
\hline $\begin{array}{ll}\text { Categories } & \text { Values } \\
\end{array}$ & 1 & 2 & 3 & 4 & 5 \\
\hline Mathematical content & $\begin{array}{c}\text { Correct and full } \\
\text { understanding of } \\
\text { concepts and topic }\end{array}$ & $\begin{array}{l}\text { Correct understanding } \\
\text { including several } \\
\text { omissions or errors }\end{array}$ & $\begin{array}{l}\text { Partial understanding } \\
\text { of topic and concepts }\end{array}$ & $\begin{array}{c}\text { Limited } \\
\text { understanding of } \\
\text { topic and concepts }\end{array}$ & $\begin{array}{c}\text { Complete lack of } \\
\text { understanding }\end{array}$ \\
\hline $\begin{array}{l}\text { Type of knowledge } \\
\text { taught in the lesson }\end{array}$ & Conceptual knowledge & $\begin{array}{c}\text { Procedural knowledge } \\
\text { with an attempt to impart } \\
\text { conceptual knowledge }\end{array}$ & $\begin{array}{c}\text { Procedural } \\
\text { knowledge only }\end{array}$ & * & * \\
\hline Main idea of the lesson & $\begin{array}{c}\text { Mathematically correct } \\
\text { formulation }\end{array}$ & $\begin{array}{l}\text { Not formulated but } \\
\text { mathematically clear }\end{array}$ & $\begin{array}{l}\text { Not clearly } \\
\text { formulated }\end{array}$ & * & * \\
\hline $\begin{array}{l}\text { Connection with prior } \\
\text { knowledge }\end{array}$ & $\begin{array}{c}\text { Cohering with content } \\
\text { taught before and after } \\
\text { the lesson }\end{array}$ & $\begin{array}{l}\text { Cohering with content } \\
\text { taught before the lesson }\end{array}$ & No coherence & * & * \\
\hline Language & Mathematically correct & $\begin{array}{l}\text { Concepts used } \\
\text { inconsistently }\end{array}$ & $\begin{array}{c}\text { Wrong mathematical } \\
\text { argument }\end{array}$ & * & * \\
\hline
\end{tabular}

* Not relevant

\section{Research Participants}

Participants in the study were 49 math teachers in elementary school (students' ages: 6-12-years). All had seven to 13 years of experience and a B.Ed. degree in math. All were women who lived and taught in the central and southern parts of Israel. Teachers were contacted using the email addresses on the national database of math teachers. Participation was voluntary and no recompense of any kind was offered. Participants acknowledged their agreement with these terms by signing an informed consent form.

\section{Research Tools and Data Collection}

The data for the study were collected by analysing lesson plans that the participating teachers prepared. We began by designing a lesson-plan framework, based on our decades of experience in training teachers, our perception of the lesson plan as a valuable method for the structuring of knowledge, and on a joint discussion of the relevant criteria for a math lesson. The purpose of this lesson-plan framework was to elicit maximum information about various aspects of teachers' mathematicalcontent knowledge.

Each lesson plan was divided into two main segments:

a. specification of the learning unit (topic of the lesson, main idea of the lesson, reference to more advanced concepts related to the topic chosen, prior knowledge that students need to understand the topic);

b. the course of the lesson, with reference to learning activities that the students would perform and additional points that require attention, such as expected responses, difficulties, important mathematical principles that should be inferred from the students' responses, and planning the order of presentation of solutions.

Accordingly, the participating teachers were asked to prepare lesson plans within the framework presented above. Each teacher was asked to write an individualised-lesson plan for an underachieving student who attended her regular class. Forty-nine lesson plans were written in all.

\section{Data Analysis}

The data were analysed in two phases: (1) category analysis of the lesson plans and (2) statistical analysis of the data obtained.

Category analysis. The category analysis was related to the aspects of mathematical content in the lesson plan, in consideration of support for the underachieving student. Quantitative values were assigned to each lesson plan based on the level of planning as determined via the categories examined: mathematical content; type of knowledge taught in the lessons; main idea of the lessons; connection to prior knowledge, and teacher's use of the language of mathematics. Table 1 presents the rubric for category analysis of lesson plans.

In Table 1, the values assigned to these categories were determined, in part, based on prior studies in the field. Thus, values 1-5 that were assigned to the category of mathematical content were based on the study by Cai (2005); values 1-3 that were assigned to the category type of knowledge taught in the lessons were based on the study by Stein, Grover, and Henningsen (1996). Similarly, we determined the values 1-3 assigned to the remaining three categories.

To check the quality and level of the mathematical content presented in the lesson, we read the lesson plan several times, paying special attention to the writing of instructions, use of concepts, solving of problems presented by the teacher, and expectations of students' difficulties. We usually identified the type of knowledge taught in the lesson on the basis of leading questions from the teacher to the students. The main idea was identified as the mathematical idea that was the answer to the question 'What was examined in the task?' The connection with prior knowledge was usually found in the length of the assignment in the lesson plan. Teachers' use of the language of mathematics was checked by examining consistency and correctness in the formulation of concepts throughout the lesson plan.

To ensure the study's validity and reliability, we jointly examined the phases of the analysis painstakingly. We held numerous brainstorming sessions, including discussions of the research questions and disclosure of the results of each of our analysis. In cases of disagreement, we reviewed the matter together until a final and fully consensual decision was reached. Also, a random 
sample of $20 \%$ of the lesson plans were analysed by an outside rater. Interrater reliability was assessed using Cohen's kappa. Agreement between raters was substantial (Cohen's kappa $=.87$ ).

Statistical analysis. To identify subgroups among the lesson plans and thus to profile math teachers' work in individualised lessons for underachieving students, a cluster analysis was performed using values of lesson plans in each of the five categories: mathematical content, main idea, type of knowledge taught, connection with prior knowledge, and teacher's math language. To examine the variance among the clusters obtained, an ANOVA test was performed. To determine the origin of the differences among clusters in each category, a Scheffe posthoc test was conducted.

\section{RESULTS}

\section{Results of the Category Analysis of the Lesson Plans}

Regarding the mathematical content of a lesson plan, we found that only $12 \%$ of teachers displayed full understanding of the mathematical content. Another $27 \%$ made small errors and omissions. Thus, $39 \%$ of the teachers demonstrated an understanding of the topic, the contents, and the principles that they wished to convey to underachieving students in an individualised lesson.

Some $28 \%$ of the participating teachers showed partial understanding of the topic to be taught. An example of partial understanding of the concept of the fraction is evidenced in one of the teachers' remarks: 'The student will understand the meaning of subtracting fractions. She will understand that a fraction represents the size of an area and will subtract sizes of areas'. When one speaks about the meaning of subtracting fractions, listeners expect to encounter the regular meaning of the subtraction operation, which the students had begun to learn in the context of rational numbers. In the case of this quotation, however, the teacher evidently construed the subtraction of fractions as the subtraction of areas. From her standpoint, every fraction represents an area, and subtracting fractions means subtracting areas. Apparently, she conflated the concept of subtraction with the substantiation of how to do it.

About one-third of the participants in the study demonstrated little or no understanding of the topic. The following case exemplifies these teachers' lack of understanding of the source of their students' difficulties. It becomes evident when, in the lesson plan itself, the teachers were asked to relate to the answers that they expected their students to give in response to tasks and to explain the reasons for their errors.

One teacher proposed to present the following problem:

'If we add $\frac{20}{21}$ and $\frac{37}{38}$, we get:

(1). A number smaller than $1 / 2$. (2). A number greater than $1 / 2$ and smaller than 1. (3). A number greater than 1 and smaller than 2. (4). A number greater than 2.

One of the wrong answers expected is no. (2)'.

Explanation of the error: 'evidently students find it hard to add fractions that have different denominators and have to be expanded'.

The teacher's assumption of the source of the difficulty makes it plain that she does not understand how to solve the problem correctly. There is no need for calculations; it suffices to judge by estimation that each fraction is close to 1 to realise that their sum would be close to 2 . The teacher did not detect the source of the students' difficulty, probably due to her poor understanding of the topics taught in this class.

Regarding the type of knowledge that should be taught, we found that $20 \%$ of the teachers intended to impart procedural knowledge only. A salient example is given in one teacher's explanation of calculating a partial quantity from a whole and expressing it with a rational number and in words:

I'll give the children the following problem: Ronnie has 12 stickers; his friend Ariel asked him to give him one-fourth of them. Ronnie agreed to do this but told Ariel that he did not know how many stickers he should give. Let's help Ronnie figure it out._l'll place 12 stickers on the desk.

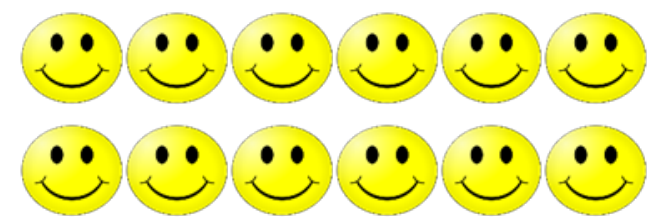

How many are there altogether? How can we know what is one-fourth of 12 ?

I'll show them the calculation as a multiplication exercise: $12 \times \frac{1}{4}=$ one-fourth of 12 .

Another example, this time relating to dividing fractions, is the following:

I'll present the students with a strategy for dividing fractions: $9: \frac{3}{4}$ and explain that this is the inverse of multiplication: $9 \times \frac{4}{3}$

The teacher makes no attempt to explain the division of fractions based on the meaning of division (partition and measurement). Instead, she dictates the algorithm to the student, after which, in her opinion, the student will remember what she needs to do and will merely have to practice the technique. The teacher does not try to explain why the algorithm 'works', where it comes from, why it yields a correct result, etc. 
Table 2. Teaching continuity. Example of teaching fraction comparisons

\begin{tabular}{|c|c|c|c|c|}
\hline $\begin{array}{l}\text { Topic of the lesson: } \\
\text { Comparing } \\
\text { fractions... }\end{array}$ & $\begin{array}{l}\text { Lesson 1: By means of area } \\
\text { models }\end{array}$ & $\begin{array}{l}\text { Lesson 2: With equal } \\
\text { denominators }\end{array}$ & $\begin{array}{c}\text { Lesson 3: With equal } \\
\text { numerators and different } \\
\text { denominators }\end{array}$ & $\begin{array}{c}\text { Lesson 4: With different } \\
\text { denominators where one } \\
\text { denominator is a multiple of } \\
\text { the other }\end{array}$ \\
\hline $\begin{array}{c}\text { Mathematical idea } \\
\text { of the lesson }\end{array}$ & $\begin{array}{l}\text { Fractions may be compared } \\
\text { by representing them as a } \\
\text { circle of fractions }\end{array}$ & $\begin{array}{l}\text { If two fractions have the same } \\
\text { denominator, the fraction } \\
\text { with the larger numerator will } \\
\text { be the larger of the two. }\end{array}$ & $\begin{array}{l}\text { If two fractions have the same } \\
\text { numerator, the fraction with } \\
\text { the smaller denominator will } \\
\text { be the larger of the two. }\end{array}$ & $\begin{array}{c}\text { In this case, a common } \\
\text { denominator can be found by } \\
\text { expanding the smaller } \\
\text { denominator into a multiple } \\
\text { of itself. }\end{array}$ \\
\hline
\end{tabular}

${ }^{\star}$ The shaded area denotes the lesson plan submitted for the study

Some $37 \%$ of the teachers prepared lesson plans that aimed to impart procedural knowledge and attempted to convey conceptual knowledge. An example is the following problem and its solution, presented by a teacher in an individualised lesson:

Presentation of the basic problem:

There are four brothers in the Cohen family. They bought a chocolate cake and divided it into equal portions. Each brother received one slice. What share did each of them get?

Danny wanted two slices. In what manner can he obtain two slices?

Solution: $\frac{1}{4}=\frac{1 \times 2}{4 \times 2}=\frac{2}{8}$. For students who do not understand, I'll show the following picture:

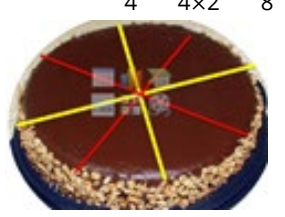

It appears that this teacher solves the problem algorithmically by expanding the fraction. She explains the answer to the question by showing a cake divided into portions. It is not clear how the student will be able to understand the relationship among the question, the expansion, and the picture.

Forty-three-percent of the teachers prepared lesson plans that aimed to impart conceptual knowledge. The following is a representative example:

The task: Nadav has 24 coloured pencils.

How many are $\frac{1}{2}$ of them? How many are $\frac{1}{3}$ of them?

Discussion question: What is the whole? What is the portion? Into how many groups should the whole be divided? How many pencils does each group contain? With the help of discourse and substantiation, I will try to make the child understand the connection between a partial quantity and part of a whole.

The next category is the way the main idea of the lesson is referenced. About half of the participating teachers expressed the central idea in mathematically correct terms. Another $10 \%$ expressed it as a goal but made it understandable. One teacher, for example, wrote, 'Students will be able to represent a fraction greater than 1 by means of an area model'. In contrast, $40 \%$ of the teachers phrased the main idea vaguely or in mathematically incorrect terms.

Regarding the connection with prior knowledge in a lesson plan, it was found that about $40 \%$ of the teachers connected the knowledge that they intended to teach in the lesson with topics and concepts that had been taught before the lesson, displaying a continuity of teaching that includes the presentation of mathematical topics and ideas taught both before and after the lesson analysed.

Below is an example of continuity manifested in the teaching of fraction comparisons, which was the topic of the teaching unit and the mathematical idea that the unit addresses (Table 2).

As shown in Table 2, the teacher managed to produce a logical continuity in teaching fraction comparisons, by extrapolating from a comparison using an area model (circles divided into equal parts) to demonstrating the algorithm that is used for the same purpose.

Furthermore, there is a direct connection between the topic taught in the lesson, as presented by the teacher for the purposes of this study, and previous lessons: Treatment of the topic begins with sensory presentation of a comparison of two fractions by means of circles, followed by a comparison of fractions on the basis of their components (common numerator or common denominator), transitioning to a comparison of fractions that have different but related denominators.

One may add another $60 \%$ of the teachers to the group of lesson planners whose works coheres with material previously taught, but their reference to the previous knowledge was fragmental and not clearly stated. Here is an example of the planning of such continuity, with the lesson plan positioned at the end of the sequence (Table 3).

As shown in Table 3, the teacher demonstrates how her lesson connects with previous lessons. Notwithstanding, the continuity presented here is debatable: Is it truly worthwhile to begin with fractions that have denominators of 3 and 6 ? Why these and not others?

In sum, a large majority of teachers connected the knowledge taught in the lesson plan with knowledge previously imparted. We may assume that they are in the habit of doing so because, in professional development settings, there is a constant emphasis 
Table 3. Teaching continuity. Example of different expressions of fractions

\begin{tabular}{|c|c|c|c|c|}
\hline Topic of lesson & $\begin{array}{l}\text { Different names for the same } \\
\text { fraction (thirds and sixths) }\end{array}$ & $\begin{array}{l}\text { Mixed numbers (thirds } \\
\text { and sixths) }\end{array}$ & $\begin{array}{l}\text { Recognising fractions that have } \\
\text { different denominators }\end{array}$ & $\begin{array}{l}\text { Different names for the same } \\
\text { fraction (fractions with } \\
\text { different denominators) }\end{array}$ \\
\hline $\begin{array}{c}\text { Mathematical idea } \\
\text { of the lesson }\end{array}$ & $\begin{array}{l}\text { One fraction can be expressed } \\
\text { in different ways (the lesson } \\
\text { deals with fractions that have } \\
\text { denominators of } 3 \text { or } 6 \text { ) }\end{array}$ & $\begin{array}{c}\text { Even a part greater than } \\
1 \text { can be } 3 \text { expressed as a } \\
\text { fraction }\end{array}$ & $\begin{array}{c}\text { Recognising additional } \\
\text { fractions that have } \\
\text { denominators other than } 3 \text { or } 6\end{array}$ & $\begin{array}{l}\text { One fraction can be } \\
\text { expressed in different ways }\end{array}$ \\
\hline
\end{tabular}

${ }^{\star}$ The shaded area denotes the lesson for which the plan was produced for the study

Table 4. Findings obtained from category analysis: Frequency of values of mathematical-content analysis categories

\begin{tabular}{|c|c|c|}
\hline Categories & Value & Frequency \\
\hline \multirow[t]{5}{*}{ Mathematical content } & 1. Correct and full understanding of concepts and topic & 6 \\
\hline & 2. Correct understating but with several omissions or errors & 13 \\
\hline & 3. Partial understanding of topic and concepts & 16 \\
\hline & 4. Limited understanding of topic and concepts & 9 \\
\hline & 5. No understanding whatsoever & 5 \\
\hline \multirow{3}{*}{$\begin{array}{l}\text { Type of knowledge } \\
\text { taught in lesson }\end{array}$} & 1. Conceptual knowledge & 21 \\
\hline & 2. Procedural knowledge with an attempt to convey conceptual knowledge & 18 \\
\hline & 3. Procedural knowledge only & 10 \\
\hline \multirow[t]{3}{*}{ Main idea of the lesson } & 1. Expressed as a mathematically correct idea & 25 \\
\hline & 2. Not expressed as an idea but clear in mathematical terms & 4 \\
\hline & 3. Not clearly expressed & 20 \\
\hline \multirow{3}{*}{$\begin{array}{l}\text { Connection with prior / future } \\
\text { knowledge }\end{array}$} & 1. Cohering with content taught before and after the lesson & 19 \\
\hline & 2. Cohering with content taught before the lesson & 27 \\
\hline & 3. No coherence & 3 \\
\hline \multirow[t]{3}{*}{ Mathematical language } & 1. Correct and consistent use of concepts & 25 \\
\hline & 2. Inconsistent use of concepts & 10 \\
\hline & 3. Erroneous mathematical argument & 14 \\
\hline
\end{tabular}

Table 5. Findings obtained from cluster analysis of lesson plans

\begin{tabular}{ccc}
\hline Cluster & Lesson plans in cluster (N) & Lesson plans in cluster (\%) \\
\hline 1 & 11 & 22.4 \\
\hline 2 & 17 & 36.7 \\
\hline 3 & 10 & 20.4 \\
\hline 4 & 10 & 20.4 \\
\hline Total & $\mathbf{4 9}$ & $\mathbf{1 0 0}$ \\
\hline
\end{tabular}

on the prior knowledge that learners need to be able to understand the current lesson. Only one-third of the teachers also looked ahead and reflected on how their teaching would continue. This is rarely an explicit requirement; its frequent omission is probably one of the reasons for the absence of this element in most of the lesson plans.

Regarding the mathematical language used, we found that $51 \%$ of the teachers demonstrated correct use of concepts in their lesson plans, $29 \%$ displayed inconsistency in using concepts, and $20 \%$ presented wrong mathematical arguments. Thus, in all, $49 \%$ of the teachers were inconsistent or erred in their use of the concepts that they wished to teach to underachieving students in an individualised lesson, as several examples show.

In the first example, the teacher explained: 'The assignment: construct circles from various derivatives of fractions and ask for two different names for the circle that you built'. She should, however, have expressed herself more precisely, instructing the children to construct a whole from various segments of fractions and name the whole in accordance with the segments of which it is built. In another example, the students were told: 'Instead of dividing the whole into additional parts, add another line to the circle'. The teacher should have explained that the entire whole should be divided into a desired number of equal parts in order to increase the number of parts within the whole. Adding an undifferentiated dividing line may cause the parts of the whole to be unequal.

Table 4 summarises the findings obtained from the category analysis by presenting the number of times each value occurs (frequency) for the examined categories.

\section{Results of the Cluster Analysis}

We performed a cluster analysis to identify subgroups among the lesson plans and, by so doing, generated a profile of math teachers' performance in individualised lessons for underachieving students. The results sorted the lesson plans in the sample into four clusters (Table 5).

Thus, each cluster accommodated 10-17 lesson plans (20-30\% of all lesson plans analysed in the study). Next, the variance among the clusters was analysed (Table 6). 
Table 6. Findings obtained from ANOVA test: Comparison of means of five factors across four clusters

\begin{tabular}{ccc}
\hline Category & Mean Square (S.D.) & F \\
\hline Main idea & $13.634(0.08)$ & $171.053^{\star \star}$ \\
\hline Mathematical content & $13.119(0.576)$ & $22.785^{\star \star}$ \\
\hline Type of knowledge taught & $0.659(0.590)$ & 1.117 \\
\hline Connection with prior knowledge & $0.257(0.356)$ & 0.722 \\
\hline Teacher's mathematical language & $8.934(0.216)$ & $41.332^{\star \star}$ \\
\hline
\end{tabular}

Distribution of lesson-plan values by factors, in accordance with four clusters

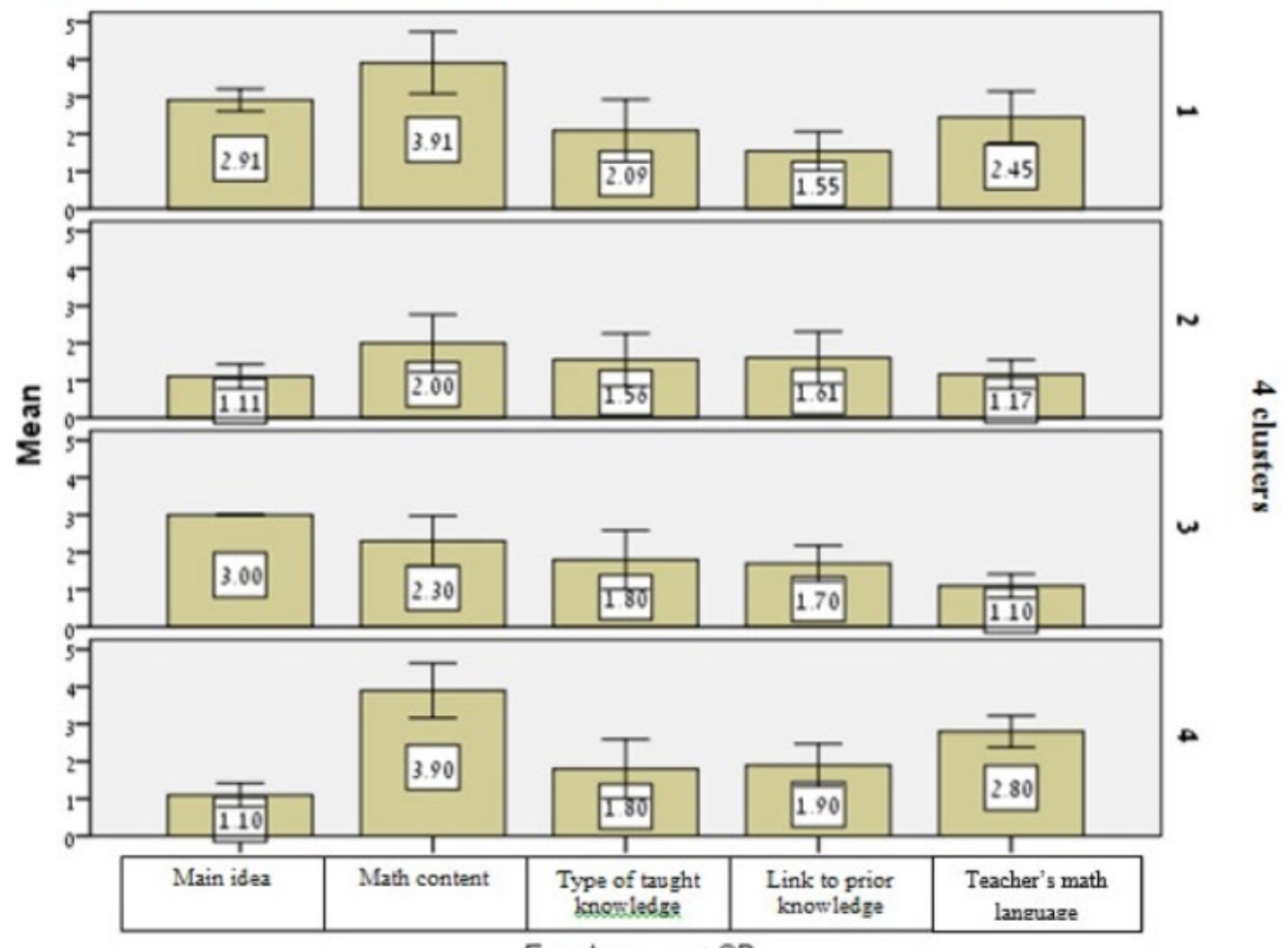

Error bars: $+/-1 \mathrm{SD}$

Figure 1. Distribution of lesson plan values by factors, in accordance with four clusters

The findings illuminate the significant difference among the clusters that was found in the variance analysis of the categories: 'main idea' $(F(3,45)=171.053, p<.001)$, 'mathematical content' $(F(3,45)=22.785, p<.001)$, and 'teacher's mathematical language' $(F(3,45)=41.332, p<.001)$. In other words, significant differences were found among teachers in their ability to express the main idea of the lesson, the mathematical content of the lesson (the extent of their understanding of the concepts and the topic), and to use mathematical language. In contrast, significant differences were not found in the following categories: 'type of knowledge taught' $(F(3,45)=1.117, p=.352)$ and 'connection with prior knowledge' $(F(3,45)=0.722, p=.544)$. The meaning of these findings is that the teachers deal with underachieving students by imparting procedural understanding while attempting to convey conceptual understanding. In addition, the lesson plans for underachieving students revealed the teachers' ability to connect what is taught in the specific individualised lesson with knowledge communicated in previous lessons. Few teachers were able to show a prospective view in their lesson plans, let alone to express such a view in student assignments and exercises.

To determine the source of the differences among the clusters in each category, a Scheffe posthoc analysis was performed. It detected significant differences in the 'main idea' category between Clusters 2 and 4 and between Clusters 1 and 3 , and in the 'mathematical content' category between Clusters 2 and 3 and between Clusters 1 and 4 . Another significant difference presented in the 'mathematical content' category between Clusters 2 and 3 and between Clusters 1 and 4 . The distribution of the four clusters is shown in Figure 1.

Now we profile each of the clusters obtained, in accordance with the presentation in Figure 1, relating to each category separately and to all five categories collectively.

Cluster 1: The main idea is not clearly formulated and the teacher has not defined a goal toward which to steer her lesson $(M=2.91)$. The mathematical content of the lesson is indicative of incomplete if not limited knowledge, reflecting a low level of mathematical-content knowledge $(M=3.91)$. The teacher's mathematical language includes erroneous mathematical argumentation $(M=2.45)$. These teachers do connect the content of their lessons with content previously taught $(M=1.55)$ but make no detectable reference in their lesson plans to the development of the concept or the mathematical principle that will be introduced in ensuing lessons. In sum, the teachers in this cluster not only limit their teaching to the procedural level but also lack the expected level of content knowledge. 
Cluster 2: The main idea of the lesson plans in this cluster is phrased correctly from the mathematical standpoint $(M=1.11)$. The mathematical content of the plan attests to correct understanding of the contents and principles that the teachers intend to present $(M=2.00)$. The teachers' mathematical language also gives evidence of thorough knowledge of the mathematical content and correct and consistent use of concepts and principles $(M=1.17)$. However, these teachers plan their lessons in such a way as to focus on imparting procedural knowledge $(M=1.56)$. They refer to the connection between the material taught in this lesson and that of previous lessons $(M=1.61)$. In sum, teachers in this cluster have enough mathematical knowledge to work with underachieving students, mainly at the procedural level.

Cluster 3: Many teachers in this cluster display correct knowledge of mathematical content $(M=2.3)$ and offer correct and consistent mathematical arguments $(M=1.10)$ but do not manage to phrase the main idea of the lesson clearly $(M=3.00)$. Also, the type of knowledge that they intend to teach in this lesson is procedural, with an attempt to convey conceptual knowledge $(M=1.8)$, and a connection with the previously taught content is detectable $(M=1.7)$. In sum, teachers in this cluster are well versed in the mathematical concepts and principles behind the content of the lesson, teach at a procedural level while attempting to convey conceptual knowledge, and usually, they connect the content of this lesson with material previously taught.

Cluster 4: These teachers' lesson plans reflect a limited understanding of mathematical content $(M=3.9)$ and a mathematical language indicative of erroneous mathematical argumentation $(M=2.8)$. However, teachers in this cluster do emphasise the formulation of the main idea of the lesson; consequently, they phrase it clearly $(M=1.1)$. The type of knowledge taught in these lessons is procedural, with an attempt to impart conceptual knowledge $(M=1.8)$. Another feature discovered is that these teachers connect the current lesson with content taught in previous lessons and also refer to its importance for understanding the ensuing lessons $(M=1.9)$. In sum, teachers in this cluster have adequate mathematical knowledge and present their lessons in a way that connects with previously taught and future content.

In conclusion, the findings reveal the existence of four types of teachers in terms of mathematical knowledge. Type 1 teachers are faulty in their mathematical knowledge. Type 2 have incomplete or limited knowledge but know how to express a mathematical idea correctly. Type 3 teachers understand mathematical content well but are not meticulous about correctly describing the math taught in the lesson. Type 4 have thorough mathematical knowledge that manifests in their lesson plans in the correct formulation of mathematical ideas and the correct and consistent use of mathematical concepts and principles. All four types of teachers, however, plan to teach their students at a procedural level while in some cases attempting to convey conceptual knowledge-probably because they expect little of their underachieving students.

\section{DISCUSSION AND CONCLUSIONS}

This research was conducted with our underlying conviction that 'Children are not born underachievers. Underachievement is a learned behaviour, and therefore it can be unlearned' (Davis \& Rimm, 2018, p. 291).

To cope with underachieving students, teachers must be aware of the students' difficulties and ways of addressing them. These methods are predicated on teachers' pedagogical mathematical knowledge, among other things. The purpose of this study was to identify several characteristics of such knowledge by analysing the lesson plans of math teachers who work with underachieving students in primary schools. Together with Valk and Broekman (1999) and Cai and Wang (2006), we showed that teachers' lessons constitute an effective tool for examining their mathematical knowledge and identifying their practices, as they work with different student populations.

Our findings reveal the existence of four distinct types of teachers in terms of mathematical-pedagogical knowledge. The results of our analysis indicate that most of the teachers are adequately knowledgeable in math. Some do not manage to clearly formulate the main idea and some fail to present all of the arguments smoothly; most, however, know the contents that the curriculum requires. Despite the differences among the teachers in mathematical knowledge and understanding, they intend to teach their students mostly at the procedural level, with an attempt, in some cases, to impart knowledge of mathematical concepts, principles, and properties. In addition, most teachers connect the content of their lessons with their students' prior knowledge but do not envision the mathematical knowledge that their students will need going forward.

These findings lead us to conclude that by having teachers write lesson plans-particularly individualised-lesson plans-and analysing the plans in various professional-development settings, the teachers will be able to develop the mathematicalpedagogical knowledge that they need for the successful management of their mathematics lessons. In the case at hand, the lesson plans hold a mirror up to teachers and reflect their ability to 'talk maths' to their students. With correct guidance, lesson plans may serve as a trigger for their professional development.

Another finding elicited by this study is the share of teachers who work with underachieving students at a procedural level, namely, $60 \%$, as our analysis of the lesson plans showed. Given that most of the participants had adequate mathematical knowledge, the origins of this kind of teaching evidently trace to teachers' affective knowledge-a disposition, tendency, emotion, or feeling about some idea (Philippson 2008). In regard to learning and teaching mathematics, affective knowledge denotes emotions, attitudes, beliefs, and expectations of teachers in regard to mathematics, the teaching of mathematics, and their students. Procedural teaching, we suggest, originates in teachers' low expectations of their struggling students and, perhaps, the belief that these students cannot engage in high-level mathematical thinking. It seems that at the very outset of their preparations for working with underachieving students, teachers expect little of them and do not plan to involve them in high levels of thinking and understanding.

Good and Brophy (1990) claim that teachers' expectations reflect their conclusions about the present and future academic achievements of a specific student. Teachers' expectations include their beliefs about students' ability to improve their 
achievements; their own potential to make the most of teaching and reteaching; the teaching methods that are best suited to each student; suitable methods of substantiation; and other matters. In a comprehensive study on math education, it was found that teachers' expectations of and beliefs about their students influenced their classroom practices (Pajares, 1992; Guberman \& Leikin, 2013; Schenke et al., 2017). Furthermore, it has been shown that teachers' explicit and implicit expectations have a powerful effect on other students (Hornstra et al., 2010; Peterson et al., 2016).

As our study demonstrates, few teachers expect their underachieving math students to attain a thorough understanding of the contents taught; instead, they focus on imparting procedural ways of coping with problems and exercises. They manifest this approach by dictating appropriate mathematical expressions with which to solve a given task without relating to the reasons for the construction of such expressions, without imparting a rule with which to solve a specific exercise, without going into why the rule was put together and why it 'works,' and so on. Many studies show that teachers' expectations rest on two foundations: conventional stereotypes about this or that group of students and the academic performance of each individual student (Hornstra et al., 2010). Numerous studies in this field indicate that the accepted stereotype in teaching underachievers is a low expectation of successfully imparting various kinds of content, as compared to that taught to high-achieving students (e.g., Zohar et al., 2001). Based on these studies, it is possible that teachers have dismal expectations of underachieving students. In our study, we showed that such expectations influence the way a teacher chooses to teach and the level of 'mathematics' that she selects for the lesson. Our participants' reference to prior knowledge while overlooking future knowledge, too, could be an indication of the impact of low expectations on the way they plan and, apparently, carry out their teaching. Along with other scholars, we espouse a contrastive approach: great expectations on the part of teachers can leverage an improvement in student achievements and learning outcomes (Beswick, 2008; Hill et al., 2018; Peltenburg et al., 2012; Scherer et al., 2016).

Furthermore, our findings reveal that teachers' instructional behaviours, at least in the stage of writing their lesson plans, are far from attentive to researchers' recommendations on how to teach such students (Bellert, 2015). Dealing with these students' struggles at the earliest possible phase is critical for their success in math studies in the future. Hence, reteaching is an opportunity for underachieving students to experience success in studying math, albeit in small measures, and in this manner to become more confident in their ability to study this subject. If the opportunity is squandered, the opposite effect may take over, to the student's disadvantage, in terms of the kind of mathematical knowledge that our participating teachers attempted to convey (procedural knowledge) and in terms of students' confidence in their potential, given the need to learn lots of 'techniques' and 'tricks' without understanding their logical underpinnings.

On the basis of the findings of the study, we conceptualise two main practical recommendations for math teachers who work with underachieving students.

1. Integrating conceptual teaching into procedural work. Scherer et al. (2016), in their overview, stress the importance of this hybridisation in working with underachieving students. As our participants' lesson plans show, teachers deal more with procedural knowledge than with conceptual knowledge, although attempts to convey the latter are sometimes made. This can be achieved by (a) emphasising the value of producing lesson plans of the kind recommended, both in teacher education and in professional-development settings, while encouraging reflective discourse among teachers in the aftermath of actual teaching and its implementation in lesson plans; (b) assigning experts in mathematics education to develop math-teaching models specifically intended for underachieving students. Thus, teachers in the field may adhere to these lessons, adjust them to their classes, or use them to pattern additional lessons.

2. Formulating of the main idea of the lesson. According to one of the recommendations arising from multiple studies on mathematics education, the preparation of lesson plans for underachieving students, and the use of said plans in teaching, should focus on a clear and precise mathematical idea (Kameenui \& Carnine, 1998). In the current study, we found that not all teachers know how to do this as one would expect. This issue, like that appearing above, needs to be dealt with at all stages of teacher education and professional development.

The implementation of both of these recommendations should be addressed at all stages of teacher education and professional development. Such preparation for math teachers is likely to have a beneficial effect on students' achievements-a point that should be examined in future research.

\section{REFERENCES}

Archer, A., \& Hughes, C. (2011). Explicit instruction: Effective and efficient teaching. New York: Guilford.

Ashman, A., \& Elkins, J. (2009). Educating students with diverse disabilities. French Forest (NSW): Prentice Hall.

Ausubel, D. P. (1978). Educational psychology: A cognitive view. New York: Holt, Rinehart and Winston Inc.

Baxter, J. A., Woodward, J., \& Olson, D. (2001). Effects of reform-based mathematics instruction on low achievers in five third-grade classrooms. The Elementary School Journal, 101(5), 529-547. https://doi.org/10.1086/499686

Bellert, A. (2015). Effective re-teaching. Australian Journal of Learning Difficulties, 20(2), $163-183$. https://doi.org/10.1080/19404158.2015.1089917

Bellert, A., \& Graham, L. (2017). Educational approaches for students experiencing learning difficulties. In J. C. Horvath, J. M. Lodge, \& J. Hattie (Eds.), From the laboratory to the classroom: Translating science of learning for teachers (pp. 229-250). Abingdon, UK: Routledge.

Beswick, K. (2008). Influencing teachers' beliefs about teaching mathematics for numeracy to students with mathematics learning difficulties. Mathematics Teacher Education and Development, 9, 3-20. 
Brophy, J. (1996). Teaching problem students. New York: Guilford.

Bryant, D. P., Bryant, B. R., Gersten, R., Scammacca, N., \& Chavez, M. M. (2008). Mathematics intervention for first-and secondgrade students with mathematics difficulties: The effects of tier 2 intervention delivered as booster lessons. Remedial and Special Education, 29(1), 20-32. https://doi.org/10.1177/0741932507309712

Cai, J. (2005). U.S. and Chinese teachers' constructing, knowing, and representations to teach mathematics. Mathematical Thinking and Learning, 7(2), 135-169. https://doi.org/10.1207/s15327833mtl0702_3

Cai, J., \& Wang, T. (2006). US and Chinese teachers' conceptions and constructions of representations: A case of teaching ratio concept. International Journal of Science and Mathematics Education, 4(1), 145-186. https://doi.org/10.1007/s10763-005-90067

Cavey, L. O., \& Berenson, S. B. (2005). Learning to teach high school mathematics: Patterns of growth in understanding right triangle trigonometry during lesson plan study. The Journal of Mathematical Behavior, 24(2), 171-190. https://doi.org/10.1016/j.jmathb.2005.03.001

Davis, G. A., \& Rimm, S. B. (2018). Gifted education: Matching instruction with needs. In Education of the gifted and talented (pp. 124). United States: Pearson.

Gervasoni, A., \& Lindenskov, L. (2011). Students with "special rights" for mathematics education. In B. Atweh, M. Graven, \& P. Valero (Eds.), Mapping equity and quality in mathematics education (pp. 307-324). New York: Springer. https://doi.org/10.1007/97890-481-9803-0_22

Good, T. L., \& Brophy, J. E. (1990). Educational psychology: A realistic approach. Longman/Addison Wesley.

Guberman, R. (2016). Development of Arithmetical Thinking: Evaluation of Subject Matter Knowledge of Pre-Service Teachers in Order to Design the Appropriate Course. International Journal of Science and Mathematics Education, 14(4), 739-755. https://doi.org/10.1007/s10763-014-9600-7

Guberman, R., \& Leikin, R. (2013). Interesting and difficult mathematical problems: changing teachers' views by employing multiple-solution tasks. Journal of Mathematics Teacher Education, 16(1), 33-56. https://doi.org/10.1007/s10857-012-9210-7

Guskey, T. R. (2010). Lessons of mastery learning. Educational Leadership, 68(2), 52-57.

Hammond, J., \& Gibbons, P. (2005). What is scaffolding. Teachers' Voices, 8, 8-16.

Hill, H. C., Charalambous, C. Y., \& Chin, M. J. (2018). Teacher Characteristics and student learning in mathematics: A comprehensive assessment. Educational Policy. https://doi.org/10.1177/0895904818755468

Hornstra, L., Denessen, E., Bakker, J., van den Bergh, L., \& Voeten, M. (2010). Teacher attitudes toward dyslexia: Effects on teacher expectations and the academic achievement of students with dyslexia. Journal of Learning Disabilities, 43(6), 515-529. https://doi.org/10.1177/0022219409355479

Isoda, M., Stephens, M., Ohara, Y., \& Miyakawa, T. (2007). Japanese lesson study in mathematics: Its impact, diversity and potential for educational improvement. Singapore: World Scientific Publishing, https://doi.org/10.1142/6339

Kameenui, E. J., \& Carnine, D. W. (1998). Effective teaching strategies that accommodate diverse learners. Englewood Cliffs, NJ: Prentice-Hall.

Karsenty, R. (2010). Nonprofessional mathematics tutoring for low-achieving students in secondary schools: A case study. Educational Studies in Mathematics, 74(1), 1-21. https://doi.org/10.1007/s10649-009-9223-z

Karsenty, R., \& Arcavi, A. (2003). Learning and thinking characteristics of low achievers in mathematics. Report submitted to the Israel Ministry of Education. Science Teaching Department, Weizmann Institute of Science (in Hebrew).

Karsenty, R., Arcavi, A., \& Hadas, N. (2007). Exploring informal mathematical products of low achievers at the secondary school level. Journal of Mathematical Behavior, 26(2), 156-177. https://doi.org/10.1016/j.jmathb.2007.05.003

Keijzer, R., \& Terwel, J. (2004). A low-achiever's learning process in mathematics: Shirley's fraction learning. Journal of Classroom Interaction, 39(2), 10-23.

Lalley, J. P., \& Miller, R. H. (2006). Effects of pre-teaching and re-teaching on math achievement and academic self-concept of students with low achievement in math. Education, 126(4), 747-756.

Le, V. Y., Stecher, B. M., Lockwood, J. R., Hamilton, L. S., Robyn, A., Williams, V. L., ... Klein, S. P. (2006). Improving mathematics and science education: A longitudinal investigation of the relationship between reform-oriented instruction and student achievement. Santa Monica, CA: Rand Corporation. https://doi.org/10.7249/MG480

Li, Y., Chen, X., \& Kulm, G. (2009). Mathematics teachers' practices and thinking in lesson plan development: A case of teaching fraction division. ZDM, 41(6), 717-731. https://doi.org/10.1007/s11858-009-0174-8

Maloney, E. A., \& Beilock, S. L. (2012). Math anxiety: Who has it, why it develops, and how to guard against it. Trends in Cognitive Sciences, 16(8), 404-406. https://doi.org/10.1016/j.tics.2012.06.008

Marzano, R. J. (2010). Reviving re-teaching. Educational Leadership, 68(2), 82-83.

Montague, M. (2011). Effective instruction in mathematics for students with learning difficulties. In C. Wyatt-Smith, J. Elkins \& S. Gunn (Eds.), Multiple perspectives on difficulties in learning literacy and numeracy (pp. 295-313). Netherlands: Springer. https://doi.org/10.1007/978-1-4020-8864-3_14 
Morgan, P. L., Farkas, G., \& Maczuga, S. (2015). Which instructional practices most help first-grade students with and without mathematics difficulties? Educational Evaluation and Policy Analysis, 37(2), $184-205$. https://doi.org/10.3102/0162373714536608

Moser Opitz, E., Freesemann, O., Prediger, S., Grob, U., Matull, I., \& Hußmann, S. (2017). Remediation for students with mathematics difficulties: An intervention study in middle schools. Journal of Learning Disabilities, 50(6), 724-736. https://doi.org/10.1177/0022219416668323

Pajares, M. F. (1992). Teachers' beliefs and educational research: Cleaning up a messy construct. Review of Educational Research, 62(3), 307-332. https://doi.org/10.3102/00346543062003307

Peltenburg, M., van den Heuvel-Panhuizen, M., \& Robitzsch, A. (2012). Special education students' use of indirect addition in solving subtraction problems up to 100-A proof of the didactical potential of an ignored procedure. Educational Studies in Mathematics, 79(3), 351-369. https://doi.org/10.1007/s10649-011-9351-0

Peterson, E. R., Rubie-Davies, C., Osborne, D., \& Sibley, C. (2016). Teachers' explicit expectations and implicit prejudiced attitudes to educational achievement: Relations with student achievement and the ethnic achievement gap. Learning and Instruction, 42, 123-140. https://doi.org/10.1016/j.learninstruc.2016.01.010

Phillipson, S.N. (2008). The optimal achievement model and underachievement in Hong Kong: An application of the Rasch model. Psychology Science Quarterly, 50(2), 147-172.

Schenke, K., Nguyen, T., Watts, T. W., Sarama, J., \& Clements, D. H. (2017). Differential effects of the classroom on African American and non-African American's mathematics achievement. Journal of educational psychology, 109(6), $794-811$. https://doi.org/10.1037/edu0000165

Scherer, P., Beswick, K., DeBlois, L., Healy, L., \& Opitz, E. M. (2016). Assistance of students with mathematical learning difficulties: How can research support practice? ZDM, 48(5), 633-649. https://doi.org/10.1007/s11858-016-0800-1

Shing, Y. L., \& Brod, G. (2016). Effects of prior knowledge on memory: Implications for education. Mind, Brain, and Education, 10(3), 153-161. https://doi.org/10.1111/mbe.12110

Stein, M. K., Grover, B. W., \& Henningsen, M. (1996). Building student capacity for mathematical thinking and reasoning: An analysis of mathematical tasks used in reform classrooms. American Educational Research Journal, 33(2), 455-488. https://doi.org/10.3102/00028312033002455

Stein, M., Silbert, J., \& Carnine, D. W. (2004). Designing effective mathematics instruction (4th ed.). Upper Saddle River, NJ: Prentice Hall.

Straehler-Pohl, H., Fernández, S., Gellert, U., \& Figueiras, L. (2014). School mathematics registers in a context of low academic expectations. Educational Studies in Mathematics, 85(2), 175-199. https://doi.org/10.1007/s10649-013-9503-5

Sullivan, Z. T. (1991). Theory for the untheoretical: Rereading and re-teaching Austen, Bronte, and Conrad. College English, 53(5), 571-579. https://doi.org/10.2307/377469

Valk, T. \& Broekman, H. G. B. (1999). The lesson preparation method: A way of investigating pre-service teachers' pedagogical content knowledge. European Journal of Teacher Education, 22(1), 11-22. https://doi.org/10.1080/0261976990220102

Van de Walle, J. A., Karp, K. S., \& Bay-Williams, J. M. (2013). Elementary and middle school mathematics: Teaching developmentally. United States: Pearson.

Van Kesteren, M. T., Rijpkema, M., Ruiter, D. J., Morris, R. G., \& Fernández, G. (2014). Building on prior knowledge: Schemadependent encoding processes relate to academic performance. Journal of Cognitive Neuroscience, 26(10), $2250-2261$. https://doi.org/10.1162/jocn_a_00630

Verschaffel, L., \& De Corte, E. (1995). Teaching realistic mathematical modeling in the elementary school. A teaching experiment with fifth graders. In L. Meira, \& D. Carraher (Eds.), Proceedings of the 19th PME Conference (pp. 105-112). Recife, Brazil: Universidade Federal de Pernambuco, Graduate Program in Cognitive Psychology.

Wyatt-Smith, C., Elkins, J., \& Gunn, S. (Eds.), (2011). Multiple perspectives on difficulties in learning literacy and numeracy. Heidelberg, Germany: Springer. https://doi.org/10.1007/978-1-4020-8864-3

Zohar, A., Degani, A., \& Vaaknin, E. (2001). Teachers' beliefs about low-achieving students and higher order thinking. Teaching and Teacher Education, 17(4), 469-485. https://doi.org/10.1016/S0742-051X(01)00007-5 